\title{
DISTRIBUTION OF HOURLY VARIABILITY INDEX OF SKY CLEARNESS
}

\author{
A Madhlopa \\ Department of Physics \& Biochemical Sciences, Malawi Polytechnic, \\ P/Bag 303, Blantyre 3, Malawi. \\ amadhlopa@poly.ac.mw
}

\begin{abstract}
Clouds affect the values of insolation for solar technology and other applications. To detect the presence of variability in the sky clearness, an hourly variability index $\left(\rho_{3}\right)$ is calculated. The present study examined the frequency distribution of this variable as a tool for assessing the utilizability of solar radiation at a site. Solar radiation data from Chileka weather station in Malawi was used to calculate $\rho_{3}$ and mean monthly variability index $\left(\rho_{3 m}\right)$ and determine the probability model for each month. It was found that $\rho_{3 m}$ was highest in April (0.20) and lowest in September (0.10), with the beta probability model fitting most of the monthly data satisfactorily. It appears that the site has great potential for application of solar technologies.
\end{abstract}

\section{INTRODUCTION}

Knowledge about the variation of the intensity of solar radiation is necessary for the development of solar systems and other applications. The intensity of solar radiation is an input variable to the design and testing of solar technologies (ISO 1994). For outdoor tests, steady-state levels of solar radiation are required when non-dynamic test methods are employed. This condition can be assured if the short-term (say, 1 hour) degree of variability in the clearness of the sky is minimal. In particular, cloud cover increases the intensity of the diffuse radiation (D) and generally reduces the intensity of global solar radiation $(\mathrm{H})$ reaching the surface of the earth. As a measure of variability in the sky clearness based on hourly data, Skartveit et al. (1998) introduced a variability index $\left(0 \leq \rho_{3} \leq 1\right)$, with low values $\left(\rho_{3} \approx 0\right)$ associated with overcast or nearly cloudless sky. Consequently, the frequency distribution of $\rho_{3}$ would indicate the potential application of solar radiation at a site.

Several authors including Skartveit and Olseth (1992), Ianetz et al. (2000) and Babu and Satyamurty (2001) have examined the distribution of $\mathrm{H}, \mathrm{D}$, clearness index $(\mathrm{k})$ and the diffuse fraction $\mathrm{f}=\mathrm{D} / \mathrm{H}$. However, information is limited on the monthly frequency distributions of $\rho_{3}$.

This study examines the distribution of $\rho_{3}$ at Chileka weather station $\left(15^{\circ} 40^{\prime} \mathrm{S}, 34^{\circ} 58^{\prime}\right.$ E) in Malawi. Probability models for $\rho_{3}$ are determined and validated using generally accepted statistical procedures.

\section{METHODOLOGY \\ Data collection}

Hourly solar radiation data captured by using a Kipp \& Zonen pyranometer installed on a horizontal surface at Chileka weather station (from 1988 to 1991) was obtained from the Department of Meteorological Services in Malawi. The quality of the data was controlled by using the guidelines reported by De Miguel et al. (2001). Missing data on global radiation was not replaced, and there were 7523 data points in the final set of data.

\section{Data processing}

The variability index $\left(\rho_{3}\right)$ was calculated according to Skartveit et al. (1998). The mean monthly hourly variability index $\left(\rho_{3 \mathrm{~m}}\right)$ was also computed, and a bin of 0.1 was used to group the values of $\rho_{3}$ with $0 \leq \rho_{3} \leq$ 0.1 as the lowest class interval for each month. In addition, the probability models 
of $\rho_{3}$ were determined for each month using generally accepted statistical rules (Kendall et al. 1987). The models were tested for the goodness of fit by using the $\chi^{2}$-statistic (Dobson 1983). The goodness of fit was satisfactory if the computed value of $\chi^{2}$ was lower than the corresponding theoretical value of this statistic for each month at $5 \%$ level of significance.

\section{RESULTS AND DISCUSSION Variability index}

The mean monthly hourly variability index $\left(\rho_{3 \mathrm{~m}}\right)$ was highest in April (0.20) and lowest in September; with intermediate values in January (0.18), February (0.17), March (0.18), May (0.18), June (0.16), July (0.14), August (0.18), October (0.14), November $(0.15)$ and December (0.18). It is observed that $\rho_{3 \mathrm{~m}}$ is relatively high from December through April. This is probably due to the prevailing humid conditions during these months (It is rainy season from November through April, and dry season from May through October in Malawi). Further, it is very cold from May through July and generally hot and dry from August through October. The month of May is in the transition period from the rainy season to the dry season while August is in the transition period from the cold into the hot weather conditions, which would account for the relatively high values of $\rho_{3 \mathrm{~m}}$ observed in May and August. The relatively low values of $\rho_{3 \mathrm{~m}}$ observed in June and July are attributed to overcast conditions while those in September and October are associated with nearly-cloudless conditions.

All the observed distributions were unimodal and positively-skewed. The modal class for all the monthly distributions was $0.0 \leq \rho_{3} \leq 0.1$ except for April and December which had a modal class of $0.1 \leq$ $\rho_{3} \leq 0.2$. This indicates that all the monthly modal values were less than or equal to 0.2 , which is relatively low compared to some group mean values of $\rho_{3}>0.5$ reported by Skartveit et al. (1998).

The beta probability distribution fitted well the monthly data from January through February, and from May through December. In addition, it was found that that the Weibull distribution described well the experimental data for March and April. Skartveit and Olseth (1992) also found that the beta and Weibull functions fitted well their data of the standard deviations of global and beam irradiance.

Frequency of invariable hours and hourly global radiation

Fig. 1 shows the monthly relative frequency of the invariable hours $\left(\rho_{3} \approx 0.0\right)$, and the mean monthly hourly global radiation $\left(\mathrm{H}_{\mathrm{m}}\right)$. For the frequency of invariable hours, it is observed that there is a distinct minimum in April (9\%) and maximum in September (40 $\%)$. This is commensurate with the values of $\rho_{3 \mathrm{~m}}$ for these two months.

For the hourly global radiation, it is observed that the mean monthly hourly global radiation is relatively high in March and from September through November, and low around May through August. This trend is attributed to astronomical effects. The sun traverses the sky overhead or close to overhead in Malawi $\left(9^{\circ} 30^{\prime} \mathrm{S}\right.$ and $\left.17^{\circ} \mathrm{S}\right)$ from September through March. The random variations in the mean monthly hourly radiation intensity are probably due to meteorological factors (such as humidity and cloud cover), as discussed above.

\section{Model performance}

The calculated values of the $\chi^{2}$-statistic were less than the corresponding theoretical values of this statistic at $5 \%$ level of significance for all the months. This indicates that the specified probability models fitted well the experimental data. 


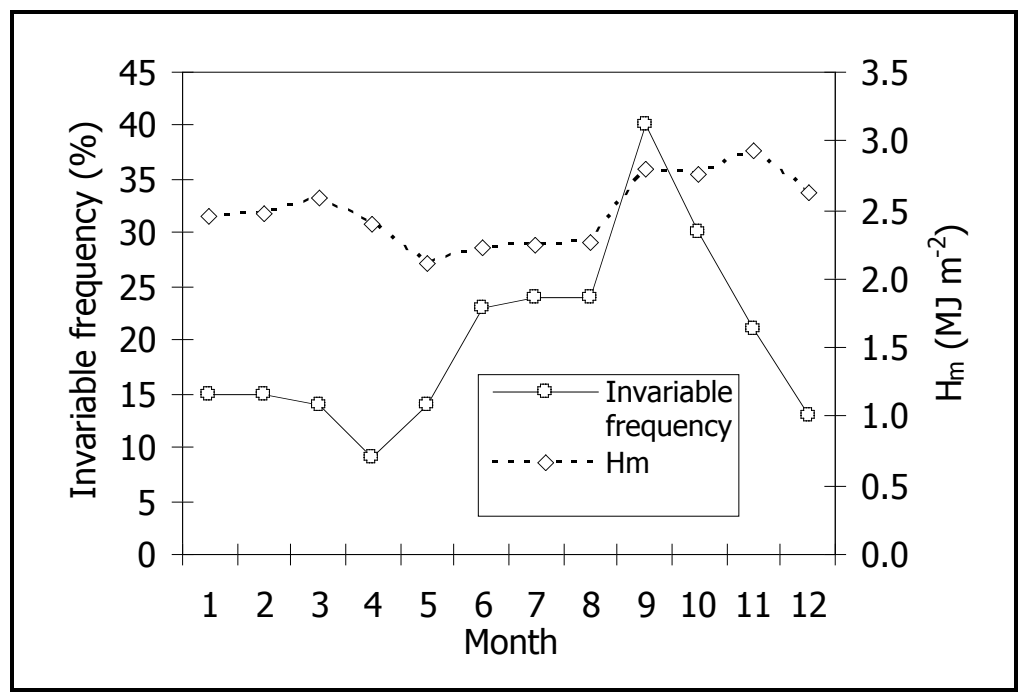

Figure 1: Monthly relative frequencies of the invariable hours and mean monthly hourly global radiation $\left(\mathrm{H}_{\mathrm{m}}\right)$.

\section{CONCLUDING REMARKS}

Frequency distributions of the hourly variability index $\left(\rho_{3}\right)$ of sky clearness have been studied. The mean monthly variability index was relatively low $\left(\rho_{3 \mathrm{~m}} \leq 0.18\right)$ throughout the year, with the beta probability model describing well the experimental observations during most of the months. It appears that the site has great potential for utilization of solar technologies. However, there is need for further work to establish and compare the long-term characteristic distribution of $\rho_{3}$ for Chileka and other sites.

\section{ACKNOWLEDGEMENTS}

The author is grateful to the Department of Meteorological Services in Malawi for providing the radiation data.

\section{REFERENCES}

Babu KS and Satyamurty VV (2001) Frequency distribution of daily clearness indices through generalized parameters. Solar Energy 70: 35-43.

De Miguel A, Bilbao J, Aguiar R, Kambezidis H and Negro E (2001)
Diffuse solar irradiation model evaluation in the North Mediterranean Belt Area. Solar Energy 70: 43-153.

Dobson AJ (1983) An introduction to statistical modeling, Chapman and Hall, London.

Ianetz A, Lyubansky V, Setter I, Evseev E $G$ and Kudish AI (2000) A method for characterization and inter-comparison of sites with regard to solar energy utilization by statistical analysis of their solar radiation data as performed for three sites in the Israel Negev region. Solar Energy 69: 283-293.

ISO (1994) Standard 9806-1: Test methods for solar collectors-part 1. Thermal performance of glazed liquid heating collectors including pressure drop. International Organization for Standardization, Geneva.

Kendall MG, Stuart A and Ord JK (1987) The Advanced Theory of Statistics, vol. 1: Distribution Theory, Charles Griffin \& Company Ltd, London.

Skartveit A and Olseth JA (1992) The probability density and autocorrelation of short-term global and beam irradiance. Solar Energy 49: 477-487. 
Skartveit A, Olseth JA and Tuft ME (1998)

An hourly diffuse fraction model with correction for variability and surface albedo. Solar Energy 63: 173-183. 